\title{
THE HYDROCHEMICAL RESPONSE OF HEILONGTAN SPRING TO THE 2010-2012 DROUGHTS OF YUNNAN PROVINCE, KUNMING, CHINA
}

Hong Liu

International Joint research Center for Karstology, Yunnan University, No. 5 Xueyun Road, Wuhua District, Kunming, Yunnan,650223, China, hongliu@ynu.edu.cn; School of Resource Environment and Earth Science, Yunnan University, Yunnan University Chenggong Campus, East Outer Ring Road, Chenggong District, Kunming 650500, China

\section{Ruiyong Chen}

School of Resource Environment and Earth Science, Yunnan University, Yunnan University Chenggong Campus, East Outer Ring Road, Chenggong District, Kunming 650500, China

\section{Huacheng Huang}

School of Resource Environment and Earth Science, Yunnan University, Yunnan University Chenggong Campus, East Outer Ring Road, Chenggong District, Kunming 650500

\section{Yinghua Zhang}

School of Resource Environment and Earth Science, Yunnan University, Yunnan University Chenggong Campus, East Outer Ring Road, Chenggong District, Kunming 650500, China

\section{Yongli Gao}

Department of Geological Sciences, University of Texas at San Antonio, One UTSA Circle, San Antonio, Texas, 78249,USA,yongli.gao@utsa.edu

\section{Abstract}

Karst waters from a mountainous recharge area drains toward basin and emerges at the edge of the basin after encountering quaternary sediments. The flow paths are partly covered by Quaternary sediments or other sedimentary rocks, which makes the spring acts as an artesian spring. The spring is more vulnerable to human activities and climate change than the classic confined karst spring. Weakly confined spring is typical in faulted karst basin. Heilongtan Springs are located at the foothills of Wulao Mountains in the northern suburb of Kunming City. They consist of Qingshuitan (QST), Hunshuitan (HST) and Xiaoshuitan (XST) springs. Spring water appears clear and muddy in QST and HST Spring, respectively, even though they share a common outlet at the southern end of QST Spring pool. From 2010 to 2012, a comprehensive hydrochemical study has been performed in Heilongtan Springs. In coincidence, the study area experienced continuously severe droughts in Yunnan Province, China, which offered an opportunity to better understand the impact of global climate change on such weakly confined karst springs. Both concentrations of hydrochemical parameters at high-resolution (every $15 \mathrm{~min}$ ) and weekly measured data during March
2010-December 2012 covering two complete hydrologic years were used to investigate the response of hydrochemical changes to prolonged and severe droughts in Yunnan from 2010 to 2012. During the drought, in addition to the decline of water table, the EC of spring decreased progressively from $319.5 \mu \mathrm{S} / \mathrm{cm}$ (yearly average, ranging from 294.0 to $339.1 \mu \mathrm{S} / \mathrm{cm}$ ) in 2010 to $299.2 \mu \mathrm{S} / \mathrm{cm}$ (ranging from 248.9 to $323.3 \mu \mathrm{S} / \mathrm{cm}$ ) in 2011 and $277.6 \mu \mathrm{S} / \mathrm{cm}$ (ranging from 237.4-311.4 $\mu \mathrm{S} /$ $\mathrm{cm}$ ) in 2012. At the same time, instead of the tendency of temperature to decrease, $\mathrm{pH}$ values increased. In 2010, the ratio of $\mathrm{Ca} / \mathrm{Mg}$ was constantly increasing from May, but in 2011 and 2012, $\mathrm{Ca} / \mathrm{Mg}$ ratios fluctuated greatly, which highlights the rapid responses of spring to precipitation. All the evidence has shown that as the drought went on, the water from the karstic aquifer kept draining out and the residence time of water got shorter. Meanwhile the water quality of the spring was more sensitive to the rain events. With a small to medium amount of precipitation, the concentrations of $\mathrm{Cl}^{-}$and $\mathrm{NO}_{3}^{-}$of the spring water started to increase a few hours after the rain, which would last 7 to 14 days. In summary, this study has shown the high sensitivity and variability of a weakly confined karst spring to environmental changes. 


\section{Introduction}

A faulted karst basin is a special type of hydrogeological unit. It originated from neotectonic movement and formed a basin-like topography surrounded by mountains, which is at least partly karstified with several hundred meters of Quaternary sediments in the basin (Wang et al., 2003). The karst water from mountainous recharge areas drains toward the basin and emerges at the edge of the basin in contact with Quaternary sediments. The flow paths to the spring are partly covered by Quaternary or Tertiary sediments or other types of rocks, which makes the spring act like an artesian spring, but it is more sensitive to climate change than the classic spring of a confined aquifer. Such karst springs are named as weakly confined spring, which are typical of springs in faulted karst basins. These karst springs play essential roles in local water supplies. Heilongtan Spring, one of the most important karst springs in Kunming, Yunnan, had been supplying water to Kunming City until the late 20th century. The spring dried out many times because of excessive water demand and urbanization of Kunming in the 1980 s to 1990 s.

Heilongtan Spring karst system is a complex and heterogeneous system in terms of structure and hydrologic characteristics (Huang \& Liu, 2015; Liu et al., 2011). However, the dynamics and origins of groundwater and the mechanism of contaminant transport are poorly understood. From 2010 to 2012, a comprehensive hydrochemical study has been performed. In coincidence, the study area experienced the prolonged and severe droughts of Yunnan Province, China, which offered an opportunity to better understand the impact of global climate change on such a weakly confined karst spring.

\section{Site Description}

Heilongtan Spring, one of the main karst springs in Kunming, China, is located in the foothills of Wulao Mountains in the northern suburb of Kunming City. The spring emerges along the east branch of Heilongtan Fault after karst water meets the Quaternary sediments at the edge of Kunming Basin. Heilongtan Spring is a typical weakly confined karst spring, with a main conduit developed below spring level bounded by a major regional fault. This spring is composed of Qingshuitan, Hunshuitan, and Xiaoshuitan springs. Qingshuitan means clear water spring and Hunshuitan means muddy water spring. They are connected by a bridge. Though all of them share an outlet at the end of Qingshuitan spring pool, the water from the 2 springs normally do not mix. Xiaoshuitan spring is an epikarstic spring with very small discharge Figure 1.

The discharge of Heilongtan Spring, based on monitoring results of 1960, ranged from $82.78 \mathrm{l} / \mathrm{s}$ to $365.5 \mathrm{l} / \mathrm{s}$ with an average flow rate of $208.3 \mathrm{l} / \mathrm{s}$. Water temperature of Qingshuitan Spring is 18 to $20^{\circ} \mathrm{C}$, which is $2-4^{\circ} \mathrm{C}$ higher than shallow karst springs in surrounding areas. Since the exploitation of groundwater in the 1960s, water levels began to decline. In the early 1980 s, due to the substantial increase in exploitation, water levels dropped by 3-4 m within 5 years. The decline of water levels caused Heilongtan Spring to be completely dry in the mid-1980s to the end of the 20th century during dry seasons. Consequently, instead of being a local industrial and municipal water supply source, the spring only serves as an important landscape feature of Heilongtan Park now.

The geological setting of the study area is very complex (Figure 1). Lithology of the Heilongtan Spring karst system corresponds to massive to thin carbonate rocks of the Paleozoic Era, which is highly folded. The lithology consists of fine-grained limestone and dolomitic limestone, interbedded with 10-30 m thick mudstone or sandstone bands. The N-S oriented Heilongtan fault is the most important fault in the study area. In the recharge area, Fengcong-depression and Fengcong-valley morphological features are well developed. The karst water is thought to flow under a Permian basalt along the east branch of Heilongtan fault,and emerges to the surface which is in contact with Quaternary sediments in the basin.

The geographical setting belongs to a north subtropical plateau monsoon climate. For the 1961-2016 period, the average annual rainfall is $996.6 \mathrm{~mm}$, and $85 \%$ of precipitation occurs between May to October. From 2010 to 2012, the entire Yunnan Province suffered a prolonged and severe drought. The annual precipitation of Kunming was $982.2 \mathrm{~mm}$ in $2009,565.8 \mathrm{~mm}$ in 2010 , $869.1 \mathrm{~mm}$ in 2011, $659.0 \mathrm{~mm}$ in 2012 and $802.1 \mathrm{~mm}$ in 2013 respectively.

\section{Methods}

A CTDP300 multi-parameter water quality meter (made by Greenspan Corporation in Australia) was placed at Qingshuitan Spring pool in the end of March 2010 to obtain water temperature, electrical conductivity, $\mathrm{pH}$, and 


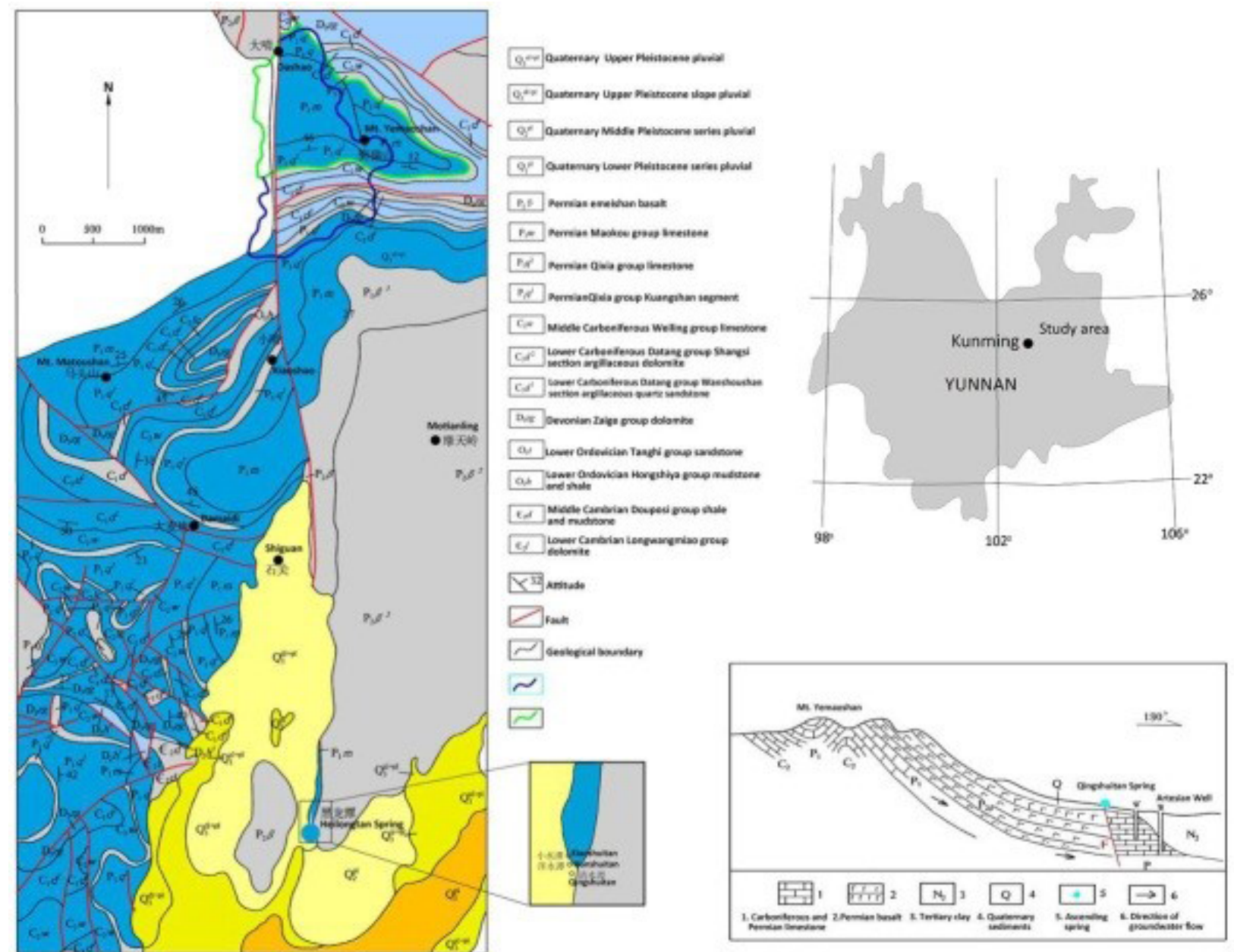

Figure 1. Hydrogeological map of the Heilongtan karst system and simplified N-S geological cross section.

water level parameters with an interval of $15 \mathrm{~min}$. Precipitation data was recorded by a RG2-M rain gauge installed on the roof of the Heilongtan Park headquarters.

Water samples from two springs (QST and HST) were collected weekly from March 2010 to November 2012, which were analyzed for concentrations of $\mathrm{Ca}^{2+}, \mathrm{Mg}^{2+}$, $\mathrm{HCO}_{3}^{-}, \mathrm{Cl}^{-}, \mathrm{NO}_{3}^{-}, \mathrm{NH}_{4}^{+}$, and $\mathrm{PO}_{4}^{3-}$. The hydrochemical samples were stored in $1000 \mathrm{ml}$ high density polyethylene bottles. $\mathrm{Ca}^{2+}$ and $\mathrm{Mg}^{2+}$ values were determined by ethylenediaminetetraacetic acid (EDTA) titration. $\mathrm{HCO}_{3}{ }^{-}$and $\mathrm{Cl}^{-}$values were measured by hydrochloric acid and argentum nitricum liquor titration, respectively, in the Karst Laboratory of the International Joint Research Center for Karstology, Yunnan University on the same day of water sampling. $\mathrm{NO}_{3}^{-}, \mathrm{NH}_{4}{ }^{+}$, and $\mathrm{PO}_{4}{ }^{3-}$ were analyzed by a series of Macherey-Nagel visocolor ${ }^{\circledR}$ ECO colorimetric boxes. The water temperature, elec- trical conductivity, and $\mathrm{pH}$ parameters of water samples were measured in situ by WTW350i.

\section{Results and Discussion}

Results of hydrochemical data are presented in Table 1. Figure 2 illustrates daily record of seasonal (wet and dry seasons) variability with fine details of storm-scale fluctuations. Figure 3 shows detailed hydrochemical variations of the spring during the drought. Though the data of water levels in Figure 2 demonstrates seasonal variability of spring water level, we did not take it in account, because a dam was built $100 \mathrm{~m}$ downstream to maintain the water level of the spring pool for the sake of tourism and some spring water was used for watering the garden daily.

Comparing with other confined karst systems, Heilong$\tan$ Spring is very sensitive to precipitation. In the 1960s, 


\begin{tabular}{|c|c|c|c|c|c|c|c|c|c|c|}
\hline Year & Item & $\begin{array}{l}\text { Water } \\
\text { temp. }\left({ }^{\circ} \mathrm{C}\right)\end{array}$ & $\mathrm{pH}$ & $\mathrm{Ca}^{2+}(\mathrm{mg} / \mathrm{L})$ & $\mathrm{Mg}^{2+}(\mathrm{mg} / \mathrm{L})$ & $\mathrm{Cl}^{-}(\mathrm{mg} / \mathrm{L})$ & $\begin{array}{l}\mathrm{HCO}_{3}^{-} \\
(\mathrm{mg} / \mathrm{L})\end{array}$ & $\begin{array}{l}\mathrm{NO}_{3}^{-} \\
(\mathrm{mg} / \mathrm{L})\end{array}$ & $\begin{array}{l}\mathrm{EC}(\mathrm{uS} / \mathrm{cm} \\
\left.25^{\circ} \mathrm{C}\right)\end{array}$ & $\mathrm{Ca} / \mathrm{Mg}$ \\
\hline \multirow[t]{4}{*}{2010} & Min. & 17.5 & 7.2 & 33.8 & 14.0 & 1.5 & 140.4 & 1.0 & 294.0 & 1.1 \\
\hline & Max. & 20.9 & 7.5 & 74.4 & 37.1 & 5.9 & 246.6 & 5.0 & 339.1 & 5.1 \\
\hline & Mean & 18.6 & 7.4 & 54.9 & 22.9 & 3.6 & 167.5 & 3.9 & 319.5 & 2.5 \\
\hline & $\mathrm{N}^{*}$ & 26,717 & 26,717 & 30 & 30 & 30 & 28 & 19 & 26,717 & 30 \\
\hline \multirow[t]{4}{*}{2011} & Min. & 17.1 & 7.2 & 47.1 & 13.9 & 1.0 & 140.4 & 1.0 & 248.9 & 2.1 \\
\hline & Max. & 20.4 & 7.7 & 67.8 & 24.0 & 3.9 & 157.2 & 8.0 & 323.3 & 4.7 \\
\hline & Mean & 18.7 & 7.4 & 54.0 & 17.8 & 2.5 & 151.4 & 5.9 & 299.2 & 3.1 \\
\hline & $\mathrm{N}^{*}$ & 32,926 & 32,926 & 17 & 17 & 17 & 17 & 17 & 32,926 & 17 \\
\hline \multirow[t]{4}{*}{2012} & Min. & 16.6 & 7.1 & 33.5 & 9.7 & 1.0 & 145.1 & 1.0 & 237.4 & 1.3 \\
\hline & Max. & 20.3 & 7.8 & 66.7 & 32.5 & 8.7 & 205.3 & 10.0 & 311.4 & 5.1 \\
\hline & Mean & 18.5 & 7.4 & 51.3 & 21.9 & 3.5 & 168.6 & 7.0 & 277.6 & 2.5 \\
\hline & $\mathrm{N}^{*}$ & 29,487 & 29,487 & 26 & 25 & 26 & 26 & 26 & 29,487 & 25 \\
\hline
\end{tabular}

Table 1. Minimum, maximum and annual mean values of water temperature (water temp.), electrical conductivity (EC) and hydrochemical parameters in Heilongtan Spring in 2010, 2011 and 2012 respectively.

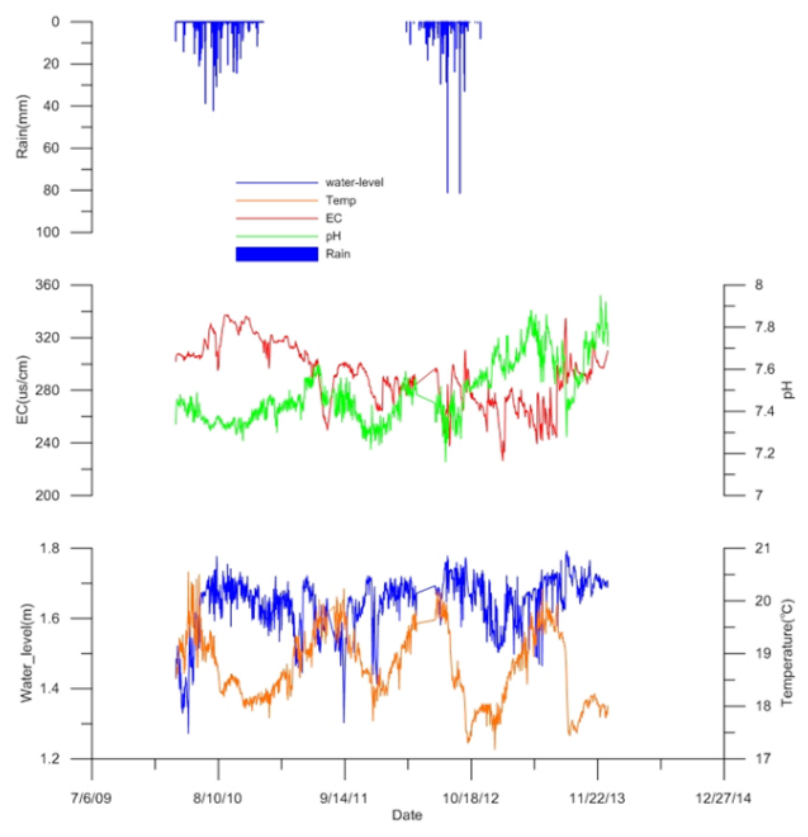

Figure 2. Daily continuous data of hydrological (water level) and hydrochemical parameters (water temperature, EC and $\mathrm{pH}$ ) in Heilongtan Spring during March 2010-December 2013, and the rainfall data of 2010 and 2012. The data between the two straight lines (27 July to 11 August of 2011 and 27 April to 25 June of 2012) was not available due to repair of the sensor. the maximum discharge was 4.4 times the minimum discharge. Based on the high-resolution (every $15 \mathrm{~min}$ ) of hydrochemical parameters data, Liu et al. (2011) discussed responses of the spring hydrochemical parameters to several scenarios of rainfall in 2010. On the scene of continuous light rainfall event, 22 April to 28 April of 2010 , with a total rainfall of $23 \mathrm{~mm}$, the physical and chemical parameters of the spring had a small range of dynamic change, with a response time lag of about a half month. At the beginning, the water temperature, conductivity and $\mathrm{pH}$ all reached a peak value, which indicates that the "old water" within conduits was pushed out. On the heavy rainfall scenario, 25 July 2010, a total rainfall of $42.2 \mathrm{~mm}$, the response of hydrochemical parameters was just 4 days of delay. It shows the dilution effect of rainwater and the electrical conductivity decreasing rapidly. With the ongoing drought, the spring became more and more sensitive to the heavy rainfall event. The response time for the storms of 4 August $(81.2 \mathrm{~mm})$ and 12 September of $2012(81.4 \mathrm{~mm})$ were less than few hours.

It could be seen clearly that the EC of the spring water decreased progressively from $319.5 \mu \mathrm{S} / \mathrm{cm}$ (yearly average, ranging from 294.0 to $339.1 \mu \mathrm{S} / \mathrm{cm}$ ) in 2010 to $299.2 \mu \mathrm{S} / \mathrm{cm}$ (ranging from 248.9 to $323.3 \mu \mathrm{S} / \mathrm{cm}$ ) in 2011 and $277.6 \mu \mathrm{S} / \mathrm{cm}$ (ranging from $237.4-311.4 \mu \mathrm{S} /$ $\mathrm{cm}$ ) in 2012 respectively. Temperature and $\mathrm{pH}$ values of spring water were relatively stable in 2010 and displayed more variations in 2011 and 2012 with a positive corre- 


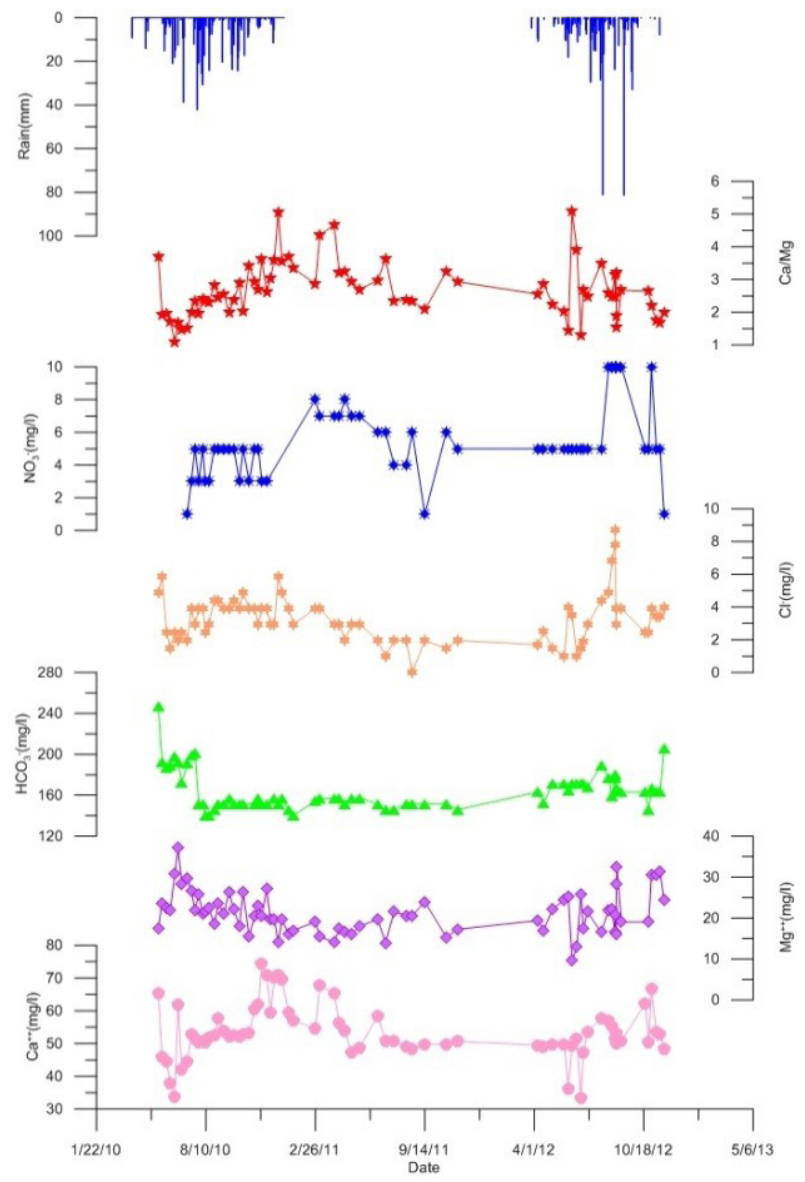

Figure 3. $\mathrm{Ca}^{2+}, \mathrm{Mg}^{2+}, \mathrm{HCO}_{3}^{-}, \mathrm{Cl}^{-}$, and $\mathrm{NO}_{3}^{-}$time variations from 2010 to 2012 in Heilongtan Spring.

lation. In general, instead of the tendency of decreasing temperature, $\mathrm{pH}$ value increased each year (Table 1 and Figure 2).

The concentration of $\mathrm{Ca}^{2+}, \mathrm{Mg}^{2+}, \mathrm{HCO}_{3}^{-}$change synchronously due to the dissolution of carbonate minerals (Yang et al., 2012). The concentration of $\mathrm{Ca}^{2+}$ normally is lower in wet seasons and higher in dry seasons. From 2010 to 2012, the annual average value of $\mathrm{Ca}^{2+}$ concentration is slightly down from $54.9 \mathrm{mg} / \mathrm{L}$ to $54.0 \mathrm{mg} / \mathrm{L}$ and $51.3 \mathrm{mg} / \mathrm{L}$ respectively. The range of $\mathrm{Ca}^{2+}$ concentration is larger in extreme drought years (2010 and 2012). The annual average concentration of $\mathrm{Mg}^{2+}$ is higher in extreme drought years with a wider range of variations. The value of $\mathrm{HCO}_{3}^{-}$has the same trend as the concentration of $\mathrm{Mg}^{2+}$. In 2010 , the ratio of $\mathrm{Ca}$ / $\mathrm{Mg}$ constantly increased from May to the end of 2010. However, in 2011 and 2012, the $\mathrm{Ca} / \mathrm{Mg}$ ratio fluctuated greatly, which implies rapid responses of the spring to precipitation.
Meanwhile the water quality of the spring was more sensitive to the rain events. With a small to medium amount of rain, the concentrations of $\mathrm{Cl}^{-}$and $\mathrm{NO}_{3}{ }^{-}$of spring water start to increase in a few hours after rain in 2012, which would last 7 to 14 days. The concentration of $\mathrm{Cl}^{-}$ has a wide range of variations in 2010 and 2012. The concentration of $\mathrm{NO}_{3}{ }^{-}$generally increased from 2010 to 2012.

All the evidence has showed that with the ongoing drought, the water from the karstic aquifer kept draining out and the residence time of water got shorter. As a consequence, the hydrochemical response of spring water to rainfall events became more rapid.

\section{Conclusions}

From 2010 to 2012, a comprehensive hydrochemical study has been performed in Heilongtan Spring. The study was conducted during prolonged and severe droughts of Yunnan Province, China, which offered an opportunity to better understand the impact of global climate change on such a vulnerable karst spring. Both concentrations of hydrochemical parameters at highresolution (every $15 \mathrm{~min}$ ) and weekly measured data during March 2010-December 2012 were used to investigate the response of hydrochemical changes to prolonged and severe droughts of Yunnan from 2010 to 2012. During the drought, besides the water table decline, the EC of the spring decreased progressively from $319.5 \mu \mathrm{S} / \mathrm{cm}$ (yearly average, ranging from 294.0 to $339.1 \mu \mathrm{S} / \mathrm{cm}$ ) in 2010 to $299.2 \mu \mathrm{S} / \mathrm{cm}$ (ranging from 248.9 to $323.3 \mu \mathrm{S} / \mathrm{cm}$ ) in 2011 and $277.6 \mu \mathrm{S} / \mathrm{cm}$ (ranging from $237.4-311.4 \mu \mathrm{S} / \mathrm{cm}$ ) in 2012. At the same time, instead of the tendency of decreasing temperature, $\mathrm{pH}$ value increased each year. In 2010, the ratio of $\mathrm{Ca} / \mathrm{Mg}$ steadily increased from May to the end of 2010 . However, in 2011 and 2012, $\mathrm{Ca} / \mathrm{Mg}$ ratio fluctuated greatly, which implies rapid responses of the spring to precipitation. All the evidence has shown that, with the ongoing drought, the water from the karstic aquifer kept draining out and the residence time of water got shorter. Meanwhile the water quality of the spring became more sensitive to rain events. With a small to medium amount of rainfall, the concentrations of $\mathrm{Cl}^{-}$ and $\mathrm{NO}_{3}^{-}$in the spring water start to increase in a few hours after rain, which would last 7 to 14 days. In summary, this study demonstrated the high sensitivity and variability of a weakly confined karst aquifer to environmental changes. 


\section{Acknowledgments}

We are grateful to two anonymous reviewers, Yongli Gao and editor for their constructive suggestions and (or) improving writing. This research is supported by the National Natural Science Foundation of China (41371040).

\section{References}

Wang Yu, Li Yan, Tan Jizhong, Zhang Gui, He Raosheng. 2003. Storage rule of karst water in fault basins. Kunming (KM), Yunnan Science and Technology Publishing House, p. 1-20.

Huang Huacheng, Liu Hong. 2015. The hydrogen and oxygen stable isotope analysis of the karst spring in Heilongtan, Carsologica Sinica, Vol. 34 (5): 445-451.

Liu Jian, Liu Hong, Yang Xiangpeng. 2011. The responses of Heilongtan karst spring to different rainfall processes, Yunnan geographic environment research, Vol. 23 (2): 73-77.

Rui Yang, Zaihua Liu, Cheng Zeng, Min Zhao. 2012. Response of epikarst hydrochemical changes to soil $\mathrm{CO}_{2}$ and weather conditions at Chenqi, Puding, SW China. Journal of Hydrology vol. 468-469: 151-158. 